Contribution à l'étude de la circulation sur de longues distances des matières premières lithiques au Paléolithique.

Les nucléus mis en forme découverts le long de la vallée de la Loire (département de l'Allier, de la Saône-et-Loire et de la Loire)

Contribution to the study of lon distance circulation of the lithic raw material during the Paleolithic. The preshaped cores found on the Loire valley (Allier, Saône-et-Loire and Loire, France)

Frédéric Surmely, Sophie Liégard, Alain Fourvel et Philippe Alix

\title{
OpenEdition
}

Journals

Édition électronique

URL : http://journals.openedition.org/paleo/1537

DOI : $10.4000 /$ paleo. 1537

ISSN : 2101-0420

Éditeur

SAMRA

Édition imprimée

Date de publication : 1 décembre 2002

Pagination : 265-274

ISSN : $1145-3370$

Référence électronique

Frédéric Surmely, Sophie Liégard, Alain Fourvel et Philippe Alix, «Contribution à l'étude de la circulation sur de longues distances des matières premières lithiques au Paléolithique. », PALEO [En ligne], 14 | 2002, mis en ligne le 18 août 2010, consulté le 20 août 2020. URL : http:// journals.openedition.org/paleo/1537 ; DOI : https://doi.org/10.4000/paleo.1537

Ce document a été généré automatiquement le 20 août 2020.

PALEO est mis à disposition selon les termes de la licence Creative Commons Attribution - Pas d'Utilisation Commerciale - Pas de Modification 4.0 International. 


\section{Contribution à l'étude de la} circulation sur de longues distances des matières premières lithiques au Paléolithique.

Les nucléus mis en forme découverts le long de la vallée de la Loire (département de l'Allier, de la Saône-et-Loire et de la Loire)

Contribution to the study of lon distance circulation of the lithic raw material during the Paleolithic. The preshaped cores found on the Loire valley (Allier, Saône-et-Loire and Loire, France)

Frédéric Surmely, Sophie Liégard, Alain Fourvel et Philippe Alix 